\title{
LA FAMILIA EN EUROPA \\ Y EL CAMBIO SOCIAL
}

Juan Díez Nicolás

\section{INTRODUCCION}

El presente trabajo pretende ser una breve y sistemática aproximación a un tema tan candente como el del impacto que un conjunto de procesos de cambio social están teniendo sobre una institución social de tanta importancia como la familia.

Como toda investigación, ésta tiene también sus limitaciones. En primer lugar, me he limitado a los países miembros del Consejo de Europa para lograr un grupo de sociedades relativamente homogéneas desde una perspectiva socio-económicocultural. Por supuesto, hay diferencias entre los 21 paises miembros que se han considerado; las más importantes, por ejemplo, entre países del sur de Europa y el resto; pero son también países muy diferenciados, algunos grandes, como Turquía, y otros más pequeños, como Islandia, Malta, Chipre, Liechtenstein, que por ello suelen desviarse muchas veces de las tendencias generales.

$\mathrm{Si}$ se pueden describir importantes diferencias entre los 21 países miembros del Consejo de Europa, puede fácilmente imaginarse las que se habrían encontrado de haber incluido los países del este de Europa o los países del resto del mundo.

La delimitación geográfica a los países señalados, por tanto, responde a la constatación de que sus experiencias socio-culturales han sido, históricamente, relativamente homogéneas (salvo, quizá, el caso de Turquía), y que en ellos, la estructura familiar ha reflejado los cambios producidos en el conjunto de la sociedad. 
En la medida en que Europa occidental, que más o menos se corresponde con el conjunto de los países miembros del Consejo de Europa (excepción hecha de alguno de los países citados), fue la primera en pasar por la revolución industrial, la primera en experimentar la transición demográfica y, en definitiva, la pionera en tantos procesos de cambio social, parece justificado que se centre la atención sobre ella, y ello por varias razones:

a) Porque interesa, per se, conocer la realidad de los cambios que se están operando en la familia en Europa, sus causas y sus consecuencias.

b) Porque lo que se observa en Europa probablemente suceda con ligeras variantes en otras sociedades no europeas dentro de algunos años.

c) Porque España, que forma parte de Europa (aunque M. Kirk, en su libro Demographic and Social Change in Europe..., se haya olvidado de ello, cometiendo un grave error no sólo político sino sobre todo científico), probablemente está ya reflejando y desde luego reflejará en los próximos años, los procesos de cambio social en las estructuras familiares que se están actualmente produciendo en otros países europeos más desarrollados en los aspectos socioeconómicos.

Una segunda limitación es la temporal. Hay ya muchos estudios sobre lo sucedido, desde el punto de vista demográfico y de la estructura familiar europea, no sólo desde antes de la revolución industrial, sino incluso desde la Segunda Guerra Mundial. Por ello, ha parecido más interesante centrar la atención en lo acontecido desde 1960 hasta el momento actual, con el fin de acentuar la perspectiva presente-futuro, más que la de pasado-presente, aunque es obvio que los tres tiempos deben ser siempre tenidos en cuenta. La limitación temporal ha facilitado, además, la recogida de datos homogéneos para los países citados, y aun así existen omisiones en los mismos por falta de datos oficiales de sus respectivos países.

El haber tomado un espacio temporal de alrededor de veinte años ha permitido, además, que se pongan aún más de manifiesto los importantes cambios que se están produciendo en las estructuras familiares europeas-occidentales en el momento actual. Cambios que, necesariamente, repercutirán sobre la sociedad en su conjunto a muy corto plazo.

Y la tercera limitación tiene que ver con los aspectos teórico-conceptuales de la familia misma. En efecto, no se va a realizar un examen exhaustivo de todos los aspectos institucionales de la familia, aunque se aludirá a muchos de ellos. Por el contrario, el trabajo se ha centrado en algunos aspectos sociológico-demográficos que parecen ser básicos para la estabilidad o el cambio de la estructura familiar. Estos aspectos se refieren sobre todo a la nupcialidad (o falta de nupcialidad), a la disolución de los matrimonios, a la procreación o natalidad ( $y$, por tanto, al control de la natalidad y al aborto). No se va a entrar de lleno en otras cuestiones muy importantes, como la función de la familia en la sociedad, la gran diversidad de estructuras familiares que coexisten en las sociedades actuales, las relaciones marido-mujer, las relaciones padres-hijos, etc. Un análisis de la familia de esas características sería difícilmente abordable en un trabajo de esta naturaleza. 
Pero, además, se ha considerado más útil ofrecer unas pinceladas muy concretas y significativas que reflejen el cambio social que se está operando en la familia europea-occidental, dejando para otros trabajos el análisis más profundo de las causas y consecuencias sociales y de otra índole que dichos cambios, sin duda, producirán.

En resumen, no se va a entrar en cuestiones relativas a si se puede ya certificar la «muerte de la familia» o cuál sea la alternativa a la «familia nuclear», o a otras cuestiones semejantes.

Como se ha dicho, el presente trabajo pretende describir, haciendo uso de un conjunto de indicadores muy contrastados por la investigación, cuáles son los cambios principales que se han producido en las estructuras familiares de los países miembros del Consejo de Europa entre 1960 y 1981.

\section{ALGUNAS TENDENCIAS ACTUALES}

La preocupación de investigadores y políticos por algunas tendencias que se han venido observando en estos últimos años en aspectos que afectan plenamente a la constitución, mantenimiento y disolución de las familias en Europa, ha cobrado tanta importancia que, en buena parte, ha sido una de las principales razones de que se convocara una Conferencia Demográfica Europea, la segunda, por parte del Consejo de Europa el pasado mes de septiembre de 1982.

D. Eversley, en un informe elaborado precisamente a petición del Comité de Expertos sobre Nupcialidad y Familia (que forma parte del Comité Director para el Estudio de los Problemas Demográficos, del Consejo de Europa), resumía las tendencias actualmente dominantes en la familia europea de la siguiente forma:

a) Matrimonio: Aumento de la edad al casarse, disminución de la nupcialidad.

b) Divorcio: En los países en que está permitido, está aumentando o estabilizándose después de un primer impacto inicial: no se pueden establecer cuáles son las tendencias respecto a segundas nupcias por esta causa.

c) Separación (sin divorcio): No existen suficientes datos disponibles.

d) Natalidad: En disminución desde 1965, estabilizándose ahora por debajo del nivel de reemplazo, pero todavía disminuyendo en países con alta natalidad, sobre todo del sur de Europa.

e) Aborto: Mucho más extendido legalmente, y obtenible en otros países (si no se permite en el propio); tiende a reducir las familias de un solo progenitor, que suelen originarse por la ilegalidad.

f) Ilegitimidad: Estable y, a veces, creciendo; algunos países han dejado de utilizar esta categoría porque la distinción ha perdido importancia y no tiene efectos legales.

g) Familias de un solo progenitor: En aumento debido a los divorcios y separaciones, y en disminución como consecuencia de la muerte prematura de alguno de los progenitores. Esta categoría puede convertirse pronto en inidentificable, es- 
pecialmente en condiciones de «monogamia sucesiva» e incluso de «poligamia sucesiva».

h) Cobabitación: En aquellos casos en que se dispone de evidencia, se observa una tendencia a aumentar: no se sabe cuánta «ilegitimidad» se produce en las uniones estables.

i) Ruptura de hogar a causa de la muerte de uno de los esposos: Se produce más tarde, lo que lleva a una cierta estabilización del porcentaje de hogares con una persona-pensionista. Sin embargo, puesto que la esperanza de vida de las mujeres todavía está aumentando en comparación con la de los hombres, es posible que no dure esta estabilidad del descenso en la proporción de hogares de una sola persona-viuda. Además, el volumen futuro de la categoría «personas ancianas que viven solas" se verá muy influido por las pautas de divorcio y de segundas y posteriores nupcias.

j) Hogares con personas disminuidas o minusválidas: Disminución de las víctimas de guerra, pero crecimiento general de la proporción de personas con 75 y más años, e incluso con 85 y más años, con una fuerte presunción de minusvalía parcial.

Resulta fácil comprender que los cambios que todos estos nuevos procesos y pautas están produciendo en la constitución, composición y disolución de la familia europea-occidental son muy importantes, y que ello tiene además que repercutir sobre las relaciones entre los miembros de la familia entre sí y con la sociedad en general. En resumen, todo parece indicar que estamos presenciando desde hace dos décadas, o incluso desde antes, un importante proceso de cambio (transformación) de la familia europea-occidental, no ya respecto al modelo tradicional de la familia extensa, sino incluso respecto al modelo de familia nuclear que surgió de la revolución industrial, de su modificación después de las dos guerras mundiales.

El ciclo vital de la familia, concepto que fue acuñado hace ya varias décadas por Hajnal, y que en España ha utilizado recientemente el sociólogo Del Campo Urbano para analizar la familia española, no sólo ha cambiado, sino que incluso puede que haga necesaria la revisión misma del concepto.

En las páginas que siguen se ofrecerán datos para verificar hasta qué punto, $y$ en qué grado, se están produciendo estos cambios en los diferentes países del Consejo de Europa.

\section{CONSTITUCION Y DISOLUCION DE LA FAMILIA}

\section{Nupcialidad}

Los cambios a que se ha hecho referencia comienzan por manifestarse en las pautas de constitución y disolución de la familia.

Así, si después de la Segunda Guerra Mundial se pudo observar, en los países europeos-occidentales, un incremento en las cifras absolutas y relativas de matrimonios (en buena parte de los matrimonios demorados a causa de la guerra), este 
aumento se detuvo aproximadamente a mediados de la década de los 60, para comenzar ull proceso inverso que, en buena parte, continúa todavía.

En efecto, el examen de las tasas brutas de nupcialidad, que se han incluido en el cuadro 1 (número de matrimonios por 1.000 habitantes) permite formular ciertas regularidades:

a) La tasa bruta de nupcialidad en 1981 (o 1980) es inferior a la de 1960 en 14 de los 20 países para los que se ofrece datos. Sólo en cinco de ellos (Chipre, Grecia, Liechtenstein, Malta e Irlanda) la tasa correspondiente a 1981 (o 1980) es superior a la de 1960 , y en uno, Gran Bretaña, es igual en ambas fechas.

b) Independientemente de lo anterior, la tendencia a lo largo de estas dos últimas décadas, prácticamente en todos los países, ha sido hacia unas tasas de nupcialidad continuamente en disminución desde 1965. Las excepciones son escasas, no parecen formar una pauta, y suelen referirse a pequeños países. Por el contrario, puede comprobarse que, en 1960, sólo tres países tenían una tasa inferior a 6 por 1.000 , mientras que, en 1980 , 9 de los 20 países tenían una tasa inferior a 6 por 1.000 , e incluso uno, Suecia, inferior al 4 por 1.000 .

\section{CUADRO 1}

Tasa bruta de nupcialidad (matrimonios por 1.000 babitantes).

Paises del Consejo de Europa, 1960-1981

\begin{tabular}{|c|c|c|c|c|c|c|c|c|c|c|}
\hline & 1960 & 1965 & 1970 & 1975 & 1976 & 1977 & 1978 & 1979 & 1980 & 1981 \\
\hline Austria $\ldots \ldots \ldots$ & 8,3 & 7,8 & 7,1 & 6,2 & 6,1 & 6,0 & 5,9 & 6,1 & 6,2 & 6,3 \\
\hline Bélgica $\ldots \ldots \ldots \ldots$ & 7,1 & 7,0 & 7,6 & 7,3 & 7,2 & 7,0 & 6,8 & 6,6 & 6,7 & - \\
\hline $\begin{array}{lllll}\text { Chipre } & \ldots & \ldots & \ldots & \ldots\end{array}$ & - & 7,6 & 8,6 & 10,6 & 7,3 & 9,7 & 9,7 & 12,0 & 8,1 & 11,2 \\
\hline Dinamarca $\ldots \ldots \ldots$ & 7,8 & 8,8 & 7,4 & 6,3 & 6,1 & 6,3 & 5,6 & 5,4 & 5,2 & 5,0 \\
\hline Francla $\ldots \ldots \ldots$ & 7,0 & 7,1 & $\mathbf{7 , 8}$ & 7,3 & 7,1 & 5,9 & 6,7 & 6,4 & 6,2 & 5,8 \\
\hline R. F de Alemania. & 9,4 & 8,3 & 7,3 & 6,3 & $\mathbf{5 , 9}$ & 5,8 & 5,4 & 5,6 & 5,9 & 5,9 \\
\hline $\begin{array}{ccccc}\text { Grecia } & \ldots & \ldots & \ldots & \ldots\end{array}$ & 7,0 & 9,4 & 7,7 & 8,4 & 6,9 & 8,2 & $\mathbf{7 , 7}$ & 8,3 & 6.5 & 7,3 \\
\hline Islandia $\ldots \ldots \ldots \ldots$ & 7,4 & 8,1 & 7,8 & 7,7 & 7,5 & 7,1 & 7,1 & 6,4 & 5,7 & 5,9 \\
\hline $\begin{array}{lllll}\text { Irlanda } & \ldots & \ldots & \ldots & \ldots\end{array}$ & $\mathbf{5 , 5}$ & 5,9 & 7,1 & 6,7 & 6,4 & 6,1 & 6,4 & 6,2 & 6,4 & - \\
\hline $\begin{array}{lllll}\text { Italia } & \ldots & \ldots & \ldots & \ldots\end{array}$ & 7,6 & 7,6 & 7,3 & 6,7 & 6,3 & 6,2 & 5,8 & 5.7 & 5,7 & - \\
\hline Liechtenstein ... ... & 5,7 & 6,8 & 5.9 & 6.8 & 6.8 & 5,9 & 5,9 & 6,0 & 7,1 & 6.9 \\
\hline $\begin{array}{lll}\text { Luxemburgo } & \ldots & \ldots\end{array}$ & 7,1 & 6,6 & 6,4 & 6,8 & 6,2 & 6,2 & 5,9 & 5,7 & 5,9 & $\mathbf{5 , 5}$ \\
\hline $\begin{array}{lllll}\text { Malta } & \ldots & \ldots & \ldots & \ldots\end{array}$ & 5,9 & 6,2 & 7,3 & $\mathbf{8 , 8}$ & 9,1 & 9,3 & 8,8 & 7.9 & 9,1 & $\mathbf{9 , 3}$ \\
\hline Países Bajos ... ... & 7,8 & 8,8 & 9,5 & 7,3 & 7,0 & 6,7 & 6,4 & 6,1 & 6,4 & 6,0 \\
\hline Noruega $\ldots \ldots \ldots$ & 6.6 & 6.5 & 7,6 & 6.5 & 6,3 & 5.9 & 58 & 5,7 & 5,4 & $\mathbf{5 . 4}$ \\
\hline Portugal $\ldots \ldots \ldots$ & 7,8 & 8,3 & 9,0 & 10,9 & 10,5 & 9,4 & 8,3 & 7,9 & 7,4 & - \\
\hline $\begin{array}{llllll}\text { España } & \ldots & \ldots & \ldots & \ldots\end{array}$ & 7,8 & 7,1 & 7,3 & 7,6 & 7,3 & 7,2 & 7,0 & 6,6 & 5,7 & $\mathbf{5 , 3}$ \\
\hline $\begin{array}{ccccc}\text { Suecia } & \ldots & \ldots & \ldots & \ldots\end{array}$ & 6,7 & 7,8 & 5,4 & 5,4 & 5,4 & 4,9 & 4,6 & 4,5 & 4,5 & 4,6 \\
\hline $\begin{array}{lllll}\text { Suiza } & \ldots & \ldots & \ldots & \ldots\end{array}$ & 7,8 & 7,6 & 7,5 & $\mathbf{5 , 5}$ & 5,1 & 5,2 & 5,1 & 5,3 & 5,6 & 5,6 \\
\hline Turquía $\ldots \ldots \ldots$ & - & - & - & - & - & - & - & - & - & - \\
\hline Reino Unido ... ... & $\mathbf{7 , 5}$ & 7,8 & 8,5 & 7,7 & 7,3 & 7,2 & 7,5 & 7.5 & 7.5 & - \\
\hline
\end{tabular}

Los diferentes informes citados (Kirk, Roussel y Festy, etc.), coinciden en que esta tendencia a la disminución de la nupcialidad puede tener un doble origen: el retraso temporal en el matrimonio, o su no celebración en absoluto en el caso de muchos individuos. Dos factores explicativos se han ofrecido para ambas posibi- 
lidades: el incremento en las relaciones pre-matrimoniales y la cohabitación, y el nuevo papel social de la mujer (especialmente por lo que respecta a su mayor participación en la población activa).

En cuanto al incremento en las relaciones pre-matrimoniales, aunque obviamente no existen datos estadísticos, sí se tiene suficiente información procedente de encuestas sociológicas y sondeos de opinión en diferentes países europeos que demuestran, sin lugar a dudas, que se ha producido en la población en general, y más especialmente entre los jóvenes, un cambio importante en el sistema de valores, de forma que la moral tradicional ha dado paso a una mayor permisividad social respecto a este tipo de relaciones pre-matrimoniales, que implica incluso una menor valoración positiva de la virginidad (o al menos una menor valoración negativa de la no-virginidad). Y, al cambiar los valores, han cambiado también los comportamientos, de forma que, en base también a diferentes investigaciones sociológicas, puede asegurarse que ha aumentado considerablemente la proporción de jóvenes que mantienen relaciones pre-matrimoniales.

De igual forma, aunque tampoco se dispone de datos estadísticos precisos, existe suficiente información que corrobora el incremento de la cohabitación de las parejas jóvenes, cohabitación que puede terminar o no en una legalización de esa situación, es decir, que puede terminar o no en una unión matrimonial. El hecho ha comenzado a revestir tal importancia en Europa que ha obligado a que la jurisprudencia se ocupe, cada vez con más frecuencia, de este tipo de parejas más o menos consensuales, dándoles un tratamiento semejante al de las parejas legalmente constituidas.

Como luego habrá ocasión de comprobar, el incremento de este tipo de parejas consensuales no sólo repercute sobre la disminución de la nupcialidad (retrasándola temporal o indefinidamente), sino también sobre la natalidad, reduciéndola.

En cuanto al nuevo papel de la mujer, no es preciso aportar aquí datos que son de sobra conocidos. Desde la Segunda Guerra Mundial la mujer ha incrementado su nivel de educación y formación profesional para trabajar fuera del hogar, ha incrementado su participación en la población activa, ha reducido considerablemente las diferencias que la separaban tradicionalmente del varón en cuanto a derechos civiles, económicos y políticos, etc.; y, en definitiva, ha logrado un mayor grado de independencia respecto al varón en todos los órdenes de la vida, por lo que el matrimonio ha dejado de ser el medio para lograr una cierta seguridad en la vida, hasta el punto de que para muchas se ha convertido en un obstáculo (real o percibido) para su propia realización personal.

Consecuentemente, estos tres factores conjuntamente ( $\mathrm{y}$ otros que podrían mencionarse) parecen contribuir a un cierto retraso (temporal o permanente) en formalizar un matrimonio. Los datos del cuadro 2 demuestran que este hecho se ha producido realmente, al menos de manera general.

Es preciso advertir que, lamentablemente, estos datos no son todo lo completos que sería deseable. Así, los datos relativos a España se refieren a todos los matrimonios, y no sólo a las primeras nupcias, y los datos de Turquía se refieren sólo a matrimonios celebrados en las ciudades. 


\section{CUADRO 2}

Edad promedio al casarse (primeras nupcias).

Países del Consejo de Europa, 1960-1981

\begin{tabular}{|c|c|c|c|c|c|c|c|c|c|c|c|c|c|c|c|c|c|c|c|c|}
\hline & \multicolumn{2}{|c|}{1960} & \multicolumn{2}{|c|}{1965} & \multicolumn{2}{|c|}{1970} & \multicolumn{2}{|c|}{1975} & \multicolumn{2}{|c|}{1976} & \multicolumn{2}{|c|}{1977} & \multicolumn{2}{|c|}{1978} & \multicolumn{2}{|c|}{1979} & \multicolumn{2}{|c|}{1980} & \multicolumn{2}{|c|}{1981} \\
\hline & $\boldsymbol{V}$ & $\boldsymbol{M}$ & $\boldsymbol{V}$ & $\boldsymbol{M}$ & $\boldsymbol{v}$ & $\boldsymbol{M}$ & $\boldsymbol{V}$ & $\boldsymbol{M}$ & $\mathbf{v}$ & $\boldsymbol{M}$ & $\boldsymbol{V}$ & $\boldsymbol{M}$ & $\boldsymbol{V}$ & $\boldsymbol{M}$ & $\boldsymbol{V}$ & $\boldsymbol{M}$ & $\boldsymbol{V}$ & $\boldsymbol{M}$ & $\boldsymbol{v}$ & $\boldsymbol{M}$ \\
\hline $\begin{array}{ccccccc}\text { Austria } & \ldots & \ldots & \ldots & \ldots & \ldots & \ldots\end{array}$ & - & - & 26,7 & 23,6 & 26,0 & 23,2 & 25,8 & 23,0 & 25,9 & 23,0 & 26,0 & 23,1 & 26,1 & 23,3 & 26,2 & 23,5 & 26,2 & 23,5 & - & - \\
\hline Bélgica $\ldots \ldots \ldots \ldots$ & - & - & - & - & - & - & - & - & - & - & - & - & - & - & - & - & - & - & - & - \\
\hline $\begin{array}{lllllll}\text { Chipre } & \ldots & \ldots & \ldots & \ldots & \ldots & \ldots\end{array}$ & - & - & - & - & - & - & 25,5 & 22,9 & 25,8 & 23,2 & 25,7 & 22,9 & 25,8 & 22,7 & 25,8 & 22,9 & 26,1 & 23,3 & 一 & 一 \\
\hline $\begin{array}{cccccc}\text { Dinamarca } & \ldots & \ldots & \ldots & \ldots & \ldots\end{array}$ & - & - & - & - & - & - & - & - & - & - & - & - & - & - & - & - & - & - & - & - \\
\hline $\begin{array}{ccccccc}\text { Francia } & \ldots & \ldots & \ldots & \ldots & \ldots & \ldots\end{array}$ & - & - & 24,9 & 22,7 & 24,7 & 22,7 & 24,7 & 22,5 & 24,7 & 22,6 & 24,8 & 22,7 & 25,0 & 22,8 & 25,0 & 22,9 & 25,1 & 23,0 & - & - \\
\hline R. F. de Alemania ... ... & 一 & - & 26,0 & 23,7 & 25,6 & 23,0 & 25,3 & 22,7 & 25,6 & 22,9 & 25,7 & 22,9 & 25,9 & 23,1 & 26,0 & 23,2 & 26,1 & 23,4 & - & - \\
\hline $\begin{array}{ccccccc}\text { Grecia } & \ldots & \ldots & \ldots & \ldots & \ldots & \ldots\end{array}$ & - & 一 & 28,7 & 23,9 & 27,9 & 22,9 & 27,2 & 22,8 & 27,5 & 22,4 & 27,6 & 22,4 & 27,4 & 22,3 & 27,3 & 22,3 & 27,1 & 22,3 & - & - \\
\hline $\begin{array}{lllllll}\text { Islandia } & \ldots & \ldots & \ldots & \ldots & \ldots & \ldots\end{array}$ & - & - & - & - & - & - & - & - & - & - & - & - & - & - & - & - & - & - & - & - \\
\hline $\begin{array}{lllllll}\text { Irlanda } & \ldots & \ldots & \ldots & \ldots & \ldots & \ldots\end{array}$ & - & 一 & - & - & - & - & - & - & - & - & - & - & - & - & - & - & - & - & - & - \\
\hline $\begin{array}{lllllll}\text { Italia } & \ldots & \ldots & \ldots & \ldots & \ldots & \ldots\end{array}$ & - & - & 28,2 & 24,4 & 27,5 & 24,1 & 22,2 & 24,0 & 27,3 & 24,2 & 27,1 & 23,9 & 27,3 & 24,2 & - & - & - & - & - & - \\
\hline Liechtenstein $\ldots \ldots \ldots$ & - & - & - & - & - & - & - & - & - & - & - & - & - & - & - & - & - & - & - & - \\
\hline $\begin{array}{llllll}\text { Luxemburgo } & \ldots & \ldots & \ldots & \ldots\end{array}$ & 一 & - & - & - & - & - & - & 一 & 25,6 & 22,7 & 一 & - & 一 & 一 & 25,9 & 23,0 & 25,9 & 23,0 & - & - \\
\hline $\begin{array}{lllllll}\text { Malta } & \ldots & \ldots & \ldots & \ldots & \ldots & \ldots\end{array}$ & - & - & - & - & - & - & - & - & - & - & - & - & - & - & - & - & - & - & - & - \\
\hline Paises Bajos . ... ... ... ... & 一 & 一 & 25,8 & 23,5 & 24,8 & 22,9 & 24,8 & 22,7 & 24,9 & 22,7 & 25,1 & 22,8 & 25,3 & 23,0 & 25,4 & 23,1 & 25,5 & 23,2 & - & - \\
\hline $\begin{array}{lllllll}\text { Noruega } \ldots & \ldots & \ldots & \ldots & \ldots & \ldots\end{array}$ & 一 & - & - & - & - & - & - & - & - & - & - & - & - & - & - & - & - & - & - & - \\
\hline $\begin{array}{cccccc}\text { Portugal } & \ldots & \ldots & \ldots & \ldots & \ldots\end{array}$ & - & - & - & - & - & - & - & - & - & - & - & - & - & - & - & - & - & - & - & - \\
\hline $\begin{array}{lllllll}\text { España } & \ldots & \ldots & \ldots & \ldots & \ldots & \ldots\end{array}$ & - & - & 28,4 & 25,2 & 27,8 & 24,9 & 27,5 & 24,7 & 27,3 & 24,6 & 27,2 & 24,5 & 27,3 & 24,5 & 26,8 & 24,2 & - & - & - & - \\
\hline $\begin{array}{lllllll}\text { Suecia } & \ldots & \ldots & \ldots & \ldots & \ldots & \ldots\end{array}$ & - & - & 26,6 & 25,2 & 26,7 & 24,3 & 27,7 & 25,2 & 27,9 & 25,2 & 28,2 & 25,4 & 28,5 & 25,7 & 28,8 & 26,1 & 29,1 & 26,3 & 一 & - \\
\hline 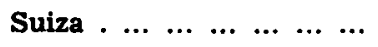 & - & - & 27,0 & 24,6 & 26,5 & 24,2 & 26,6 & 24,3 & 26,8 & 24,4 & 27,1 & 24,7 & 27,3 & 24,9 & 27,4 & 24,9 & - & - & - & - \\
\hline 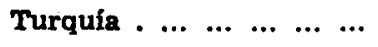 & - & - & 27,2 & 22,6 & 26,6 & 22,0 & 26,0 & 20,8 & 26,0 & 21,7 & 26,1 & 21,8 & 25,7 & 21,5 & 26,0 & 21,8 & - & - & 一 & - \\
\hline $\begin{array}{lllll}\text { Reino Unido } & \ldots & \ldots & \ldots & \ldots\end{array}$ & 一 & 一 & 25,0 & 22,6 & 24,4 & $\mathbf{2 2 , 4}$ & 25,0 & 22,8 & 25,1 & 22,8 & 25,1 & 22,8 & 25,2 & 22,8 & 25,2 & 22,9 & 25,3 & 23,0 & - & - \\
\hline
\end{tabular}


En todo caso, la pauta general que muestran estos datos pueden resumirse así:

a) La edad promedio de los varones al casarse es aproximadamente dos años superior a la de las mujeres.

b) De manera general, la edad promedio al casarse, que había ido reduciéndose desde la década de los 50, como consecuencia de las mayores facilidades de los jóvenes para independizarse económicamente de los padres, comienza a elevarse a partir de 1975, aproximadamente. En algunos países el cambio se produce unos años antes o unos años después, pero desde 1975, aproximadamente, se observa en general este incremento en la edad promedio al casarse.

c) Las excepciones más importantes a esta pauta son Grecia, España y Turquía, probablemente porque todavía estaban en el estadio previo de reducción de la edad al casarse, por la tardía emancipación de los jóvenes del hogar paterno.

\section{Disolución de los matrimonios}

Pero no se trata sólo de que ahora la gente se case en menor proporción que antes, o que los que se casan lo hagan más tarde. Otro hecho que afecta a la estabilidad de la familia es que los matrimonios duran menos tiempo, se rompen con mayor frecuencia.

El matrimonio se puede romper por razones naturales (muerte de uno de los cónyuges) o por razones jurídicas (disolución del vínculo). Los países de Europa occidental han ido progresivamente aceptando primero la separación o la anulación de los matrimonios, y finalmente el divorcio (con mayores o menores condicionamientos, según los países).

La ruptura del matrimonio por razones naturales ha perdido importancia relativa como consecuencia de la disminución de la mortalidad y del consiguiente incremento de la esperanza de vida, tanto para mujeres como para varones. La muerte separa cada vez menos, o por lo menos más tarde, a los cónyuges. La duración teórica de la unión matrimonial se ha incrementado por esta causa en más del 100 por 100 a lo largo de este siglo.

En todo caso, y por lo que respecta a esta causa de ruptura del matrimonio, debe señalarse que, debido al mayor incremento relativo de esperanza de vida entre las mujeres, cada vez es más frecuente que la causa de la ruptura sea la muerte del varón (porque su mortalidad es mayor, y porque, como se ha dicho, suele ser dos o tres años mayor, como promedio, que su esposa). Ello explica que el número de viudas sea mucho mayor (dos veces mayor en algunos países) que el de viudos.

Pero, puede que para compensar esta mayor posibilidad de duración de los matrimonios, la ruptura por causas sociales, jurídicas, ha aumentado extraordinariamente. Si bien es difícil obtener datos sobre separaciones, existen ya estadísticas fiables sobre el número de divorcios en los países europeos-occidentales, tal y como puede comprobarse en el cuadro 3. 
Los datos demuestran inequívocamente que, salvo muy contadas excepciones, la tasa de divorcidad es más alta en 1981 que en 1960, y en bastantes casos es casi el doble o más del doble que en 1960.

Pero lo más notable es que en algunos casos la tasa de divorcidad se acerca cada vez más a la de nupcialidad, como sucede en Suecia y Dinamarca. Así, en Suecia, en 1960, hubo 6,7 matrimonios por cada 1.000 habitantes y 1,2 divorcios también por cada 1.000 habitantes; en 1981, las correspondientes tasas fueron de 4,6 y 2,4 por 1.000. En otras palabras, en 1960 hubo en aquel país más de cinco matrimonios por cada divorcio, mientras que en 1981 no llegó a dos matrimonios por divorcio.

\section{CUADRO 3}

Tasa bruta de divorcios (divorcios por 1.000 babitantes). Paises del Consejo de Europa, 1960-1981

\begin{tabular}{|c|c|c|c|c|c|c|c|c|c|c|}
\hline & 1960 & 1965 & 1970 & 1975 & 1976 & 1977 & 1978 & 1979 & 1980 & 1981 \\
\hline Austria $\ldots \ldots \ldots$ & 1,1 & 1,2 & 1,4 & 1,4 & 1,5 & 1,6 & 1.7 & 1,7 & 1,8 & 1,8 \\
\hline Bélgica $\ldots \ldots \ldots$ & 0,5 & 0,6 & 0,7 & 1,1 & 1,3 & 1,3 & 1,4 & 1,4 & 1,5 & - \\
\hline Chipre $\ldots \ldots \ldots$... & - & 0,3 & 0,3 & 0,2 & 0,2 & 0,3 & 0,3 & 0,3 & 0,3 & 0,3 \\
\hline Dinamarca $\ldots \ldots \ldots$ & 1,5 & 1,4 & 1,8 & 2,6 & 2.6 & 2,6 & 2,6 & 2,5 & 2,7 & 2,8 \\
\hline Francia $\ldots \ldots \ldots \ldots$ & 0,7 & 0,7 & 0,8 & 1,2 & 1,2 & 1,4 & 1,5 & 1,7 & 1.7 & - \\
\hline R. F. de Alemania. & 0,9 & 1,0 & 1,3 & 1,7 & 1,8 & 1,2 & 0,5 & 1,3 & 1.6 & - \\
\hline Grecia $\ldots \ldots \ldots$ & 0,3 & 0,4 & 0,4 & 0,4 & 0,4 & 0,5 & 0,5 & 0,5 & 0,7 & 0,6 \\
\hline Islandia $\ldots \ldots \ldots \ldots$ & 0,7 & 0,0 & $\mathbf{T}, 2$ & 1,8 & 1,7 & 1,8 & 1,8 & 1,7 & 1,9 & 2,0 \\
\hline $\begin{array}{lllll}\text { Irlanda } & \ldots & \ldots & \ldots & \ldots\end{array}$ & - & - & - & - & - & - & - & - & - & 一 \\
\hline 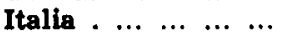 & - & - & - & 0,2 & 0,2 & 0,2 & 0,2 & 0,2 & 0,2 & - \\
\hline Liechtenstein ... ... & 0.3 & 0,1 & 0,4 & - & - & - & - & - & - & - \\
\hline Luxemburgo $\ldots . .$. & 0,5 & 0,4 & 0,6 & 0,6 & 1,0 & 1,1 & 1,5 & 1,2 & 1,6 & 1,4 \\
\hline $\begin{array}{lllll}\text { Malta } & \ldots & \ldots & \ldots & \ldots\end{array}$ & - & - & - & - & - & - & 一 & - & - & - \\
\hline Paises Bajos ... ... & 0,5 & 0,5 & 0,0 & 1,5 & 1,5 & 1,6 & 1,6 & 1,7 & 1,8 & 2,0 \\
\hline Noruega $\ldots \ldots \ldots$ & 0,7 & 0,7 & 0,8 & 1,4 & 1,4 & 1,5 & 1,5 & 1,6 & 1,6 & - \\
\hline Portugal . ... . . . . & 0,1 & 0,1 & 0,1 & 0,2 & 0,5 & 0,8 & 0,7 & 0,6 & - & - \\
\hline España $\ldots \ldots \ldots$ & - & - & - & - & - & - & - & - & - & - \\
\hline $\begin{array}{lllll}\text { Suecia } & \ldots & \ldots & \ldots & \ldots\end{array}$ & 1,2 & 1,2 & 1,6 & 3,1 & 2,6 & 2,5 & 2,4 & 2,4 & 2,4 & 2,4 \\
\hline $\begin{array}{lllll}\text { Suiza } & \ldots & \ldots & \ldots & \ldots\end{array}$ & 0,8 & 0,8 & 1,0 & 1,4 & 1,5 & 1,7 & 1,7 & 1,6 & 1,7 & - \\
\hline Turquía.$\ldots \ldots \ldots$ & - & - & - & - & - & - & - & - & - & - \\
\hline Reino Unido ... ... & 0,5 & 0,7 & 1,1 & 2,3 & 2,4 & 2,5 & 2,7 & $\mathbf{2 , 7}$ & 2,8 & - \\
\hline
\end{tabular}

Los datos parciales existentes para algunos de los países aquí estudiados parecen demostrar que gran parte de los divorcios se producen en matrimonios de corta duración, es decir, en los primeros años. De igual forma, parece que el promedio de hijos en los matrimonios que se rompen por divorcios es algo menor, a igualdad de duración, que en los matrimonios que no se rompen; sin embargo, la evidencia no es todavía concluyente respecto a la secuencia causal: se rompen con más facilidad los matrimonios con pocos hijos (o sin hijos), o bien se tienen menos hijos en aquellos matrimonios con tendencia a romperse mediante divorcio.

Lo que sí parece comprobado es que el incremento en el número de divorcios está también produciendo un incremento en el número de matrimonios en segun. das o posteriores nupcias, y que la proporción de quienes contraen nuevas nupcias es superior entre los varones. 


\section{Celibato}

Teniendo en cuenta los anteriores hechos, cabría deducir que estaría aumentando la proporción de solteros, tanto varones como mujeres. Los datos, sin embargo, todavía no permiten generalizar sobre esta cuestión. Existen variaciones importantes de unos países a otros y de unos grupos de edad a otros.

\section{CUADRO 4}

Porcentaje de solteros, por sexo, en el grupo de edad de 45.49 años. Países del Consejo de Europa, 1960-1981

\begin{tabular}{|c|c|c|c|c|c|c|}
\hline & \multicolumn{2}{|c|}{1950} & \multicolumn{2}{|c|}{1960} & \multicolumn{2}{|c|}{1970} \\
\hline & Varones & Mujeres & Varones & Mujeres & Varones & Mujeres \\
\hline $\begin{array}{llllll}\text { Austria } & \ldots & \ldots & \ldots & \ldots & \ldots\end{array}$ & 10,0 & 14,3 & 8,0 & 12,1 & 6,7 & 11,4 \\
\hline Bélgica $\ldots \ldots \ldots \ldots \ldots$ & 9,1 & 10,3 & 9,0 & 9,2 & 8,3 & 7,7 \\
\hline $\begin{array}{lllllll} & & & & & & \end{array}$ & - & - & - & - & - & - \\
\hline Dinamarca $\ldots \ldots \ldots$ & 9,7 & 13,9 & 9,7 & 9,4 & 9,4 & 6,7 \\
\hline Francia $\ldots \ldots \ldots$ & 10,7 & 10,2 & 10,0 & 8,6 & 9,9 & 8,2 \\
\hline R. F. de Alemania ... & 6,8 & 12,7 & 4,9 & 9,4 & 4,4 & 0,8 \\
\hline $\begin{array}{cccccc}\text { Grecia } & \ldots & \ldots & \ldots & \ldots & \ldots\end{array}$ & 7,3 & 5,1 & 6,9 & 6,2 & 6,2 & 7,1 \\
\hline Islandia $\ldots \ldots \ldots \ldots$ & - & - & - & - & - & - \\
\hline $\begin{array}{cccccc}\text { Irlanda } & \ldots & \ldots & \ldots & \ldots & \ldots\end{array}$ & 32,0 & 26,3 & 30,5 & 22,1 & 29,9 & 20,4 \\
\hline $\begin{array}{llllll}\text { Italia } & \ldots & \ldots & \ldots & \ldots & \ldots\end{array}$ & 9,3 & 15,0 & 9,3 & 13,7 & 11,1 & 13,8 \\
\hline $\begin{array}{lllll}\text { Liechtenstein } & \ldots & \ldots & \ldots\end{array}$ & - & - & - & - & - & - \\
\hline Luxemburgo . ... ... ... & - & - & - & - & - & - \\
\hline $\begin{array}{cccccc}\text { Malta } & \ldots & \ldots & \ldots & \ldots & \ldots\end{array}$ & - & - & - & - & - & - \\
\hline Países Bajos $\ldots \ldots \ldots$ & 9,1 & 13,5 & 7,7 & 11,0 & 7,0 & 8,3 \\
\hline 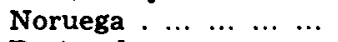 & 15,5 & 20,5 & 13,4 & 13,0 & 12,9 & 8,4 \\
\hline Portugal.$\ldots \ldots \ldots \ldots$ & 12,2 & 17,2 & 11,5 & 15,9 & 8,2 & 12,5 \\
\hline España $\ldots \ldots \ldots$ & 10,0 & 15,0 & 9,5 & 13,5 & 9,0 & 12,0 \\
\hline $\begin{array}{llllll}\text { Suecia } & \ldots & \ldots & \ldots & \ldots & \ldots\end{array}$ & 16,2 & 18,5 & 14,5 & 11,0 & 14,0 & 7,8 \\
\hline $\begin{array}{llllll}\text { Suiza } & \ldots & \ldots & \ldots & \ldots & \ldots\end{array}$ & 13,4 & 19,2 & 11,9 & 15,3 & 9,2 & 12,0 \\
\hline Turquía $\ldots \ldots \ldots \ldots \ldots$ & - & - & - & - & - & - \\
\hline Reino Unido $\ldots \ldots \ldots$ & 9,8 & 15,2 & 9,5 & 10,5 & 9,8 & 7,8 \\
\hline
\end{tabular}

Así, y como consecuencia de la reducción general del promedio de edad al casarse durante la década de los 50 y de los 60 , la proporción de casados aumentó hasta 1970, aunque en algunos países esa proporción se ha reducido desde esa fecha. El cuadro 4 presenta los datos disponibles hasta el momento, ya que los datos del censo de 1980 ó 1981 (según los países) todavía no son fácilmente asequibles en todos los países implicados. La tendencia general de los datos de este cuadro 4, que sólo llegan hasta 1970, demuestran que:

a) Se redujo en esas dos décadas la proporción de solteros en el grupo de edad de 45 a 49 años, tanto entre los varones como entre las mujeres, y con carácter general en todos los países para los que se ha contado con datos.

b) La proporción de mujeres solteras en ese grupo de edad es generalmente mayor que la de varones, debido al desequilibrio entre varones y mujeres (por la 
menor mortalidad de éstas y por la frecuente diferencia de dos años entre ambos sexos para el emparejamiento, lo que reduce el «mercado» potencial de maridos para cada cohorte de mujeres). Este desequilibrio es especialmente notable en algunos países que sufrieron pérdidas muy considerables de varones durante la Segunda Guerra Mundial.

c) Las diferencias que subsisten entre países demuestran la existencia de profundas diferencias socioculturales y económicas entre ellos.

\section{FAMILIA Y REPRODUCCION}

\section{Natalidad}

Tradicionalmente se había afirmado que la función primordial del matrimonio era la procreación. Por supuesto que los países europeos-occidentales, en la medida en que fueron pioneros en los procesos de industrialización, urbanización, modernización, secularización, etc., fueron también pioneros en pasar por el proceso de transición demográfica (de altas tasas de mortalidad y natalidad a bajas tasas de mortalidad y natalidad).

La disminución de la natalidad, acelerada a lo largo del siglo xx, alcanzó unos niveles que se consideraron mínimos hacia la Segunda Guerra Mundial. Al acabar la contienda, sin embargo, se produjo un espectacular incremento de las tasas brutas de natalidad que ha sido conocido como el «baby boom». Después de una cierta reducción posterior de las tasas, éstas volvieron a aumentar ligeramente hasta la década de los 60 , la década del desarrollo y del optimismo desarrollista.

Pero, desde esas fechas, la natalidad ha continuado descendiendo casi ininterrumpidamente hasta la actualidad. Los datos que se presentan en el cuadro 5 demuestran los siguientes hechos:

a) La tasa bruta de natalidad en 1981 (o 1980) es inferior a la de 1960 en todos los países salvo en Irlanda.

b) En 1960 había siete países con tasas brutas de natalidad superiores a 20 por 1.000; en 1980 sólo había dos países. En 1960 sólo cuatro países tenían tasas brutas de natalidad inferiores a 17 por 1.000 (y de ellos, sólo uno - Suecia- inferior a 14 por 1.000); en 1980,11 de los 20 países tenían una tasa inferior a 14 por 1.000 .

c) La disminución ha sido, en casi todos los casos, ininterrumpida, con excepciones muy ocasionales y que, por lo general, no pueden considerarse alteraciones a esta tendencia.

d) Sólo en algunos países, como Austria, Francia o el Reino Unido, parece detectarse un cierto incremento de la natalidad en los dos o tres últimos años, aunque es pronto todavía para afirmar que se trate de una tendencia que vaya a consolidarse e incluso a ampliarse a otros países. En todo caso, la alarma ante esta situación se está ya reflejando en una gran preocupación en varios gobierno. 
de Europa occidental, como se puso de manifiesto en la reciente Conferencia Demográfica Europea al examinar las políticas demográficas y hacia la familia de los países miembros del Consejo de Europa.

\section{CUADRO 5}

Tasa bruta de natalidad (nacimientos por 1.000 babitantes). Países del Consejo de Europa, 1960-1981

\begin{tabular}{|c|c|c|c|c|c|c|c|c|c|c|}
\hline & 1960 & 1965 & 1970 & 1975 & 1976 & 1977 & 1978 & 1979 & 1980 & 1981 \\
\hline Austria & 17,8 & 17,9 & 15,2 & 12,5 & 11,6 & 11,4 & 11,4 & 11,5 & 12,1 & 12,4 \\
\hline Bélgica. & 16,9 & 16,3 & 14,6 & 12,2 & 12,3 & 12,4 & 12,4 & 12,6 & 12,6 & - \\
\hline 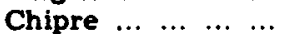 & - & 23,2 & 19,2 & 16,0 & 18,7 & 18,4 & 19,3 & 20,5 & 21,7 & 20,6 \\
\hline Dinamarca $\ldots \ldots \ldots$ & 16,6 & 18,0 & 14,4 & 14,2 & 12,9 & 12,2 & 12,2 & 11,6 & 11,2 & 10,4 \\
\hline $\begin{array}{ccccc}\text { Francia } & \ldots & \ldots & \ldots & \ldots\end{array}$ & 17,8 & 17,8 & 16,7 & 14,1 & 13,6 & 14,0 & 13,8 & 14,2 & 14,9 & 14,9 \\
\hline R. $F$ de Alemania. & 17,4 & 17,7 & 13,4 & 9,7 & 9,8 & 9,5 & 9,4 & 8,5 & 10,1 & 10,1 \\
\hline 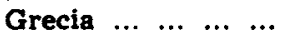 & 18,9 & 17,7 & 16,5 & 15,7 & 16,0 & 15,4 & 15,5 & 15,5 & 15,4 & 14,5 \\
\hline Islandia $\ldots \ldots \ldots$ & 28,0 & 24,6 & 18,7 & 20,1 & 19,5 & 18,0 & 18,6 & 19,8 & 19,8 & 18,8 \\
\hline $\begin{array}{lllll}\text { Irlanda } & \ldots & \ldots & \ldots & \ldots\end{array}$ & 21,5 & 22,1 & 21,8 & 21,2 & 21,0 & 21,1 & 21,2 & 21,5 & 21,9 & - \\
\hline $\begin{array}{lllll}\text { Italia } & \ldots & \ldots & \ldots & \ldots\end{array}$ & 17,9 & 18,8 & 16,5 & 14,8 & 13,9 & 13,1 & 12,5 & 11,8 & 11,3 & - \\
\hline Liechtenstein ... . .. & 22,8 & 20,4 & 19,8 & 12,8 & 14,3 & 12,8 & 12,3 & 14,3 & 15,1 & 14,6 \\
\hline Luxemburgo $\ldots \ldots$ & 16,0 & 16,0 & 13,0 & 11,1 & 10,8 & 11,2 & 11,2 & 11,2 & 11,4 & 12,1 \\
\hline $\begin{array}{llll}\text { Malta } & \ldots & \ldots & \ldots\end{array}$ & 26,1 & 17,6 & 16,3 & 19,0 & 18,7 & 18,8 & 18,1 & 18,5 & 17,6 & 16,7 \\
\hline Países Bajos ... & 20,8 & 18,9 & 18,3 & 13,0 & 12,8 & 12,5 & 12,6 & 12,5 & 12,8 & 12,5 \\
\hline Noruega . ... ... & 17,3 & 17,8 & 16,6 & 14,1 & 13,3 & 12,6 & 12,8 & 12,7 & 12,5 & 12,3 \\
\hline Portugal . ... & 23,8 & 23,0 & 20,0 & 18,1 & 19,3 & 18,6 & 17,1 & 16,3 & 16,3 & - \\
\hline $\begin{array}{llll}\text { España } & \ldots & \ldots & \ldots\end{array}$ & 21,8 & 21,1 & 19,6 & 18,8 & 18,8 & 18,0 & 17,3 & 16,1 & 15,1 & 14,1 \\
\hline $\begin{array}{lllll}\text { Suecia } & \ldots & \ldots & \ldots & \ldots\end{array}$ & 13,7 & 15,8 & 13,7 & 12,6 & 12,0 & 11,6 & 11,3 & 11,6 & 11,7 & 11,3 \\
\hline $\begin{array}{l}\text { Suiza } \ldots \\
\ldots\end{array}$ & 17,6 & 18,8 & 15,8 & 12,3 & 11,7 & 11,5 & 11,3 & 11,3 & 11,6 & 11,5 \\
\hline Turquia . ... ... ... & - & - & - & - & - & - & - & - & - & - \\
\hline Reino Unido ... ... & 17,5 & 18,4 & 16,3 & 12,5 & 12,1 & 11,8 & 12,3 & 13,1 & 13,5 & 13,1 \\
\hline
\end{tabular}

\section{Control de la natalidad}

Independientemente de las políticas pro-natalistas que algunos paises europeos están adoptando (Francia es posiblemente el que destaca en esta actividad), la casi totalidad de ellos están convencidos de que corresponde a las parejas decidir libre y responsablemente no sólo el número de hijos que tienen, sino cuando los tienen (es decir, el espaciamiento entre unos hijos y otros).

Numerosos estudios sociológicos, y los datos estadísticos disponibles, demuestran sin lugar a dudas la utilización masiva de medios anticonceptivos en todos los países europeo-occidentales, lo que ha permitido reducir a promedios próximos a dos el número de hijos por pareja. El tamaño ideal, que todavía en la década de los 60 se encontraba en un promedio de tres hijos por familia (en un intervalo de dos a cuatro), se ha visto ya reducido a dos en estas últimas décadas.

Pero la utilización de métodos de control de natalidad no sólo ha permitido reducir el número total de hijos que se tienen, sino que ha permitido, asimismo, controlar mejor su espaciamiento. La pauta general parecía ser la de tener los hijos en los primeros años de matrimonio, y, puesto que la edad promedio al ca- 


\section{CUADRO 6}

Edad media de las mujeres al tener el primer bijo y al tener cualquier bijo.

Paises del Consejo de Europa, 1960-1981

\begin{tabular}{|c|c|c|c|c|c|c|c|c|c|c|c|c|c|c|c|c|c|c|c|c|}
\hline & \multicolumn{2}{|c|}{1960} & \multicolumn{2}{|c|}{1965} & \multicolumn{2}{|c|}{1970} & \multicolumn{2}{|c|}{1975} & \multicolumn{2}{|c|}{1976} & \multicolumn{2}{|c|}{1977} & \multicolumn{2}{|c|}{1978} & \multicolumn{2}{|c|}{1979} & \multicolumn{2}{|c|}{1980} & \multicolumn{2}{|c|}{1981} \\
\hline & $10^{\circ}$ & $C$ & $10^{\circ}$ & C & $10^{\circ}$ & C & $10^{\circ}$ & c & $10^{\circ}$ & C & $10^{\circ}$ & C & $10^{\circ}$ & C & $1 .^{\circ}$ & C & $10^{\circ}$ & C & $10^{\circ}$ & C \\
\hline ustria & 24,8 & 27,6 & 24,1 & 27,1 & 23,8 & 26,4 & 24,0 & 26,0 & 24,1 & 26,0 & 24,1 & 26,0 & 24,2 & 25,9 & 24,2 & 25,9 & 24,3 & 25,9 & 24,3 & 25,9 \\
\hline $\begin{array}{cccccc}\text { Bélgica } & \ldots & \ldots & \ldots & \ldots & \ldots\end{array}$ & 25,1 & - & 24,4 & - & 24,0 & - & 24,1 & - & 24,3 & - & 24,4 & - & - & - & - & - & - & - & - & - \\
\hline $\begin{array}{ccccccc}\text { Chipre } & \ldots & \ldots & \ldots & \ldots & \ldots & \ldots\end{array}$ & - & - & - & - & - & 一 & 24,0 & 26,4 & 24,0 & 26,3 & 24,4 & 26,7 & 24,2 & 26,5 & 23,4 & 26,0 & 23,8 & 26,1 & - & 一 \\
\hline $\begin{array}{cccccc}\text { Dinamarca } & \ldots & \ldots & \ldots & \ldots & \ldots\end{array}$ & 23,1 & 26,8 & 22,7 & 26,1 & 23,7 & 26,2 & 24,0 & 26,4 & 24,1 & 26,6 & 24,1 & 26,6 & 24,4 & 26,7 & 24,5 & 26,8 & 24,6 & 26,9 & - & - \\
\hline 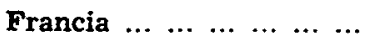 & 24,7 & 27,6 & 24,4 & 27,3 & 24,4 & 27,2 & 24,5 & 26,7 & 24,6 & 26,6 & 24,6 & 26,5 & - & 26,6 & - & 26,7 & - & 26,8 & - & 一 \\
\hline R. F. de Alemania ... ... & - & - & 24,9 & 27,6 & 24,3 & 27,4 & 24,8 & 27,0 & 24,9 & 27,0 & 25,0 & 27,0 & 25,1 & 27,0 & 25,2 & 27,0 & 25,2 & 27,0 & - & - \\
\hline $\begin{array}{ccccccc}\text { Grecia } & \ldots & \ldots & \ldots & \ldots & \ldots & \ldots\end{array}$ & 25,6 & 28,0 & 25,4 & 28,0 & 24,0 & 26,8 & 23,6 & 26,0 & 23,5 & 25,7 & 23,5 & 25,6 & 23,4 & 25,4 & 23,3 & 25,2 & 23,3 & 25,1 & - & - \\
\hline $\begin{array}{lllllll}\text { Islandia } & \ldots & \ldots & \ldots & \ldots & \ldots & \ldots\end{array}$ & - & - & 26,9 & 21,4 & 26,0 & 21,3 & 25,7 & 21,8 & 25,7 & 21,8 & 25,9 & 21,8 & 25,8 & 21,8 & 26,1 & 22,0 & 26,2 & 21,9 & - & - \\
\hline $\begin{array}{llllllll}\text { Irlanda } & \ldots & \ldots & \ldots & \ldots & \ldots & \ldots\end{array}$ & 27,5 & 31,6 & 26,5 & 30,7 & 25,8 & 29,6 & 25,2 & 28,8 & 25,4 & 28,8 & 25,5 & 28,8 & 25,5 & 28,3 & - & - & - & - & - & - \\
\hline $\begin{array}{lllllll}\text { Italia } & \ldots & \ldots & \ldots & \ldots & \ldots & \ldots\end{array}$ & 26,0 & 29,0 & 25,4 & 28,7 & 25,0 & 28,1 & 24,7 & 27,5 & 24,7 & 27,4 & 24,8 & 27,4 & 24,9 & 27,3 & 24,9 & 27,2 & 一 & 一 & - & - \\
\hline $\begin{array}{lllll}\text { Liechtenstein } & \ldots & \ldots & \ldots & \ldots\end{array}$ & - & 28,3 & - & 27,4 & - & 30,3 & - & 27,6 & - & 28,1 & - & 28,0 & - & 27,4 & - & 27,6 & - & - & - & - \\
\hline $\begin{array}{llllll}\text { Luxemburgo } & \ldots & \ldots & \ldots & \ldots\end{array}$ & - & - & - & - & - & - & - & - & - & - & - & - & - & - & - & - & - & - & - & - \\
\hline $\begin{array}{llllllll}\text { Malta } & \ldots & \ldots & \ldots & \ldots & \ldots & \ldots\end{array}$ & - & - & - & - & - & - & - & - & - & - & - & - & - & - & - & - & - & 一 & - & - \\
\hline Países Bajos . ... ... ... . . & 25,6 & 29,6 & 24,7 & 28,6 & 24,2 & 27,4 & 25,0 & 26,9 & 25,1 & 27,0 & 25,3 & 27,2 & 25,4 & 27,3 & 25,6 & 27,4 & 25,6 & 27,5 & - & 一 \\
\hline $\begin{array}{lllllll}\text { Noruega } \ldots & \ldots & \ldots & \ldots & \ldots & \ldots\end{array}$ & 25,4 & 28,8 & 23,7 & 27,2 & 23,6 & 26,1 & 24,2 & 25,9 & 24,4 & 26,1 & 24,5 & 26,2 & 24,9 & 26,5 & 25,0 & 26,6 & 25,2 & 26,7 & - & - \\
\hline $\begin{array}{llllll}\text { Portugal } & \ldots & \ldots & \ldots & \ldots & \ldots\end{array}$ & 25,1 & 29,0 & 25,0 & 29,2 & 24,4 & 28,7 & 24,0 & 27,7 & 23,7 & 27,0 & 23,6 & 26,8 & 23,6 & 26,7 & 23,6 & 26,7 & - & - & 一 & $\rightarrow$ \\
\hline $\begin{array}{ccccccc}\text { España } & \ldots & \ldots & \ldots & \ldots & \ldots & \ldots\end{array}$ & - & - & - & - & - & - & - & 28,8 & - & 28,5 & - & 28,5 & - & 28,4 & - & 28,3 & - & - & - & - \\
\hline $\begin{array}{llllllll}\text { Suecia } & \ldots & \ldots & \ldots & \ldots & \ldots & \ldots\end{array}$ & - & - & - & - & - & - & 24,5 & 26,7 & 24,8 & 26,9 & 24,9 & 27,1 & 25,1 & 27,4 & 25,8 & 27,7 & 26,0 & 27,8 & - & 一 \\
\hline $\begin{array}{llllllll}\text { Suiza } & \ldots & \ldots & \ldots & \ldots & \ldots & \ldots\end{array}$ & 26,0 & 28,7 & 25,3 & 27,9 & 25,1 & 27,6 & 25,7 & 27,6 & 25,9 & 27,7 & 26,2 & 27,9 & 26,3 & 28,0 & 26,4 & 28,0 & 26,4 & 28,1 & - & - \\
\hline Turquía $\ldots \ldots \ldots \ldots$ & 19,1 & 20,9 & 19,3 & 24,0 & 19,1 & 25,1 & 19,5 & 25,3 & 19,9 & 25,7 & 20,4 & 25,4 & 20,1 & 25,6 & - & - & - & - & - & - \\
\hline $\begin{array}{lllll}\text { Reino Unido } & \ldots & \ldots & \ldots & \ldots\end{array}$ & 24,8 & 27,7 & 24,1 & 27,0 & 23,8 & 26,2 & 24,6 & 26,3 & 24,7 & 26,4 & 24,9 & 26,5 & 25,0 & 26,6 & 25,0 & 26,7 & 25,0 & 26,7 & - & - \\
\hline
\end{tabular}


sarse había tendido a disminuir, la edad promedio de las mujeres al tener su primer hijo también había tendido a reducirse. Los datos que se presentan en el cuadro 6 permiten deducir algunas conclusiones:

a) La edad promedio de las mujeres al tener el primer hijo es, por necesidad, inferior a la edad promedio al considerar todos los hijos. (Los datos para Islandia tienen que ser, necesariamente, erróneos y probablemente la fuente estadística de la que se han obtenido simplemente intercambió los datos correspondientes al primer hijo y a cualquier número de hijos.)

b) La edad promedio de las mujeres al tener sus hijos es, en 1980, inferior al promedio correspondiente a 1960, salvo en Dinamarca, República Federal de Alemania, Suecia, Suiza, Turquía y Reino Unido.

c) Puesto que la pauta general, en casi todos los países, parece demostrar que la edad al tener hijos disminuyó hasta mediados de la década de los 70 , para elevarse generalmente después, parece lógico pensar que esta pauta está relacionada causalmente con la pauta antes señalada respecto a la edad al contraer primeras nupcias. Ello explica que aquellos países que antes han comenzado a retrasar la edad al casarse, sean también los primeros en mostrar un retraso en la edad en que tienen sus hijos; éste es, en general, el caso de los países citados.

En cuanto a la reducción del número de hijos, queda plena e inequívocamente demostrada con los datos que se presentan en el cuadro 7 . En efecto, con la ex-

\section{CUADRO 7}

Porcentaje de bijos de orden cuarto o superior (sobre 100 nacidos vivos). Paises del Consejo de Europa, 1960-1981

\begin{tabular}{|c|c|c|c|c|c|c|c|c|c|c|}
\hline & 1960 & 1965 & 1970 & 1975 & 1976 & 1977 & 1978 & 1979 & 1980 & 1981 \\
\hline $\begin{array}{llllll}\text { Austria } & \ldots & \ldots & \ldots & \ldots\end{array}$ & 16,4 & 17,5 & 14,4 & 11,0 & 10,1 & 9,4 & $\mathbf{8 , 7}$ & 8,1 & 7,5 & 7,1 \\
\hline Bélgica $\ldots \ldots \ldots \ldots$ & 21,8 & 20,2 & 15,0 & 9,3 & 8,0 & 7,4 & 7,2 & - & - & - \\
\hline $\begin{array}{lllll}\text { Chipre } & \ldots & \ldots & \ldots & \ldots\end{array}$ & - & 28,5 & 15,3 & 9,1 & 7,0 & 6,2 & 5,0 & 4.7 & 4,4 & - \\
\hline Dinamarca ... ... ... & 17,6 & 15,1 & 7,4 & 5,5 & 5,4 & 5,0 & 4,5 & 4,5 & 4,4 & - \\
\hline Francia $\ldots \ldots \ldots$ & 24,9 & 20,5 & 15,5 & 9,5 & 7,9 & 7,2 & 6,8 & 6,6 & 6,6 & - \\
\hline R. F. de Alemania. & 13,4 & 13,2 & 11,6 & 8,5 & 7,6 & 6,8 & 6,3 & 6,1 & 5,9 & - \\
\hline Grecia ... ... ... ... & 13,4 & 9,1 & 7,2 & 6,8 & 5,8 & 5,5 & 5,1 & 4,9 & 5,0 & - \\
\hline Islandia $\ldots \ldots \ldots \ldots$ & 32,1 & 29,5 & 18,9 & 13,9 & 13,1 & 12,9 & 11,9 & 11,6 & 12,1 & - \\
\hline $\begin{array}{lllll}\text { Irlanda } & \ldots & \ldots & \ldots & \ldots\end{array}$ & 44,6 & 41,3 & 34,8 & 27,7 & 27,0 & 26,8 & 27,3 & - & - & - \\
\hline 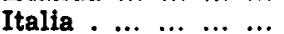 & 20,0 & 17,5 & 15,0 & 10,8 & 10,0 & 9,2 & 8,5 & 7,6 & - & - \\
\hline Liechtenstein ... ... & - & - & - & - & - & - & - & - & - & - \\
\hline $\begin{array}{lll}\text { Luxemburgo } & \ldots & \ldots\end{array}$ & 13,1 & 13,2 & 10,8 & 7,0 & 6,4 & $\mathbf{5 , 2}$ & 5,0 & 4,9 & $\mathbf{4 , 5}$ & - \\
\hline $\begin{array}{llllll}\text { Malta } & \ldots & \ldots & \ldots & \ldots\end{array}$ & - & - & - & - & - & - & - & - & - & - \\
\hline Paises Bajos ... ... & 25,1 & 19,7 & 12,0 & 5,6 & 5,5 & $\mathbf{5 , 5}$ & 5,4 & 5,6 & 6,1 & 6,5 \\
\hline Noruega . ... ... ... & 15,4 & 16,0 & 11,5 & 6,4 & 6,4 & 5,6 & 5,7 & 5,8 & 5,5 & - \\
\hline Portugal $\ldots \ldots$... $\ldots$ & 31,6 & 32,2 & 28,0 & 19,9 & 16,9 & 15,1 & 13,9 & 13,1 & - & - \\
\hline España $\ldots \ldots \ldots \ldots$ & - & - & - & 15,4 & 14,7 & 14,1 & 13,2 & 12,3 & - & - \\
\hline $\begin{array}{lllll}\text { Suecia } & \ldots & \ldots & \ldots & \ldots\end{array}$ & - & - & - & - & 4,6 & 4,6 & 4,9 & 5,3 & 5,5 & 一 \\
\hline $\begin{array}{lllll}\text { Suiza } & \ldots & \ldots & \ldots & \ldots\end{array}$ & 16,8 & 13,6 & 9,8 & 5,8 & 5,5 & 5,1 & 5,0 & 4,7 & 4,7 & - \\
\hline Turquía....... & 34,4 & 46,2 & 48,7 & 47,0 & 46,0 & 40,8 & 43,0 & $=$ & $=$ & 一 \\
\hline Reino Unido ... ... & 16,7 & 16,3 & 12,6 & 7,8 & 7,3 & 6,9 & 6,9 & 7,1 & 7,2 & \\
\hline
\end{tabular}


cepción de Suecia y Turquía, por razones muy diferentes, la proporción de hijos nacidos que ocupaban el cuarto lugar es muy inferior en 1980 a 1960. (El caso de Suecia se explica porque el nivel en que se mueve es de por si muy bajo, y porque además no existen datos antes de 1976.)

El cambio en este aspecto ha sido extraordinario. En efecto, mientras que en 1960 , en cuatro países (Islandia, Irlanda, Portugal y Turquía), más de un tercio de los niños nacidos ocupaban el rango cuarto o superior, en 1980 no había más que un solo país en el que esa proporción llegase a uno de cada diez (Islandia).

\section{Reproducción}

La reducción tan drástica de la natalidad en los países europeo-occidentales tiene, por supuesto, consecuencias importantes para el futuro, en cuanto que está reduciendo extraordinariamente no sólo el crecimiento actual de su población, sino su potencial de crecimiento futuro, es decir, su capacidad de reproducción.

Tradicionalmente se han utilizado dos tasas de reproducción para medir esta capacidad potencial. La tasa bruta de reproducción nos dice el número de bijas que deja detrás de sí una mujer nacida hoy que, a los largo de sus años reproductivos (15 a 49 años) tuviese hijos de acuerdo con las tasas específicas de fecundidad que tienen ahora, realmente, las mujeres comprendidas en ese grupo de edad. La tasa neta de reproducción es igual, pero descuenta de este cálculo las mujeres que no se reproducirán (ni nacerán) como consecuencia de la mortalidad previsible (y que también se toma como igual a la actualmente observada en las mujeres de distintos grupos de edad). Como se ve en el cuadro 8 , toda tasa de reproducción superior a uno indicará que cada mujer dejará detrás de sí algo más que una bija al concluir su período reproductivo. Puede observarse también que, aunque las tasas netas son siempre (tienen que serlo) inferiores a las tasas brutas, las diferencias son muy pequeñas, lo que indica que la mortalidad femenina en todos estos países es mínima.

Pero lo más importante de este cuadro es señalar que, en general, la capacidad reproductora de las poblaciones europeas-occidentales está muy seriamente comprometida, pues se encuentra por debajo del nivel de simple reemplazamiento (por debajo de 1). En 1980, de los 14 países de los que se tienen datos sobre su tasa neta de reproducción, sólo tres se encontraban por encima del nivel de reemplazamiento: Chipre, Grecia e Islandia. De seguir, pues, los actuales niveles de natalidad en los países europeo-occidentales, el volumen absoluto de su población tenderá a disminuir. El problema no sólo es el de que la población europea disminuirá sus cifras absolutas respecto a las actuales, sino que el resto del mundo está orientado a un ritmo de crecimiento considerablemente acelerado, lo que implica que el peso relativo de la población europea será cada vez menor. (Como ejemplo basta señalar que la población de los países en vías de desarrollo era el doble que la de los países desarrollados en 1960 , es el triple en 1980, y será el cuádruple en el año 2000; y esta diferencia será todavía más amplia si, de los países desarrollados, se toman solamente los de Europa occidental.) 


\section{CUADRO 8}

Tasa bruta y tasa neta de reproducción (hijos por mujer en cada coborte bipotética).

Paises del Consejo de Europa, 1960-1981

\begin{tabular}{|c|c|c|c|c|c|c|c|c|c|c|c|c|c|c|c|c|c|c|c|}
\hline \multicolumn{2}{|c|}{1960} & \multicolumn{2}{|c|}{1965} & \multicolumn{2}{|c|}{1970} & \multicolumn{2}{|c|}{1975} & \multicolumn{2}{|c|}{1976} & \multicolumn{2}{|c|}{1977} & \multicolumn{2}{|c|}{1978} & \multicolumn{2}{|c|}{1979} & \multicolumn{2}{|c|}{1980} & \multicolumn{2}{|c|}{1981} \\
\hline $\begin{array}{l}\text { 蜔 } \\
\text { F- }\end{array}$ & $\sum_{[=[}^{R}$ & $\underset{m}{\stackrel{p}{m}}$ & $\sum_{F}^{R}$ & $\underset{|c|}{\stackrel{\alpha}{m}}$ & $\sum_{i=1}^{\infty}$ & $\underset{f}{\stackrel{0}{0}}$ & ${ }_{2}^{0}$ & 蜔 & $\sum_{i=1}^{R}$ & $\begin{array}{c}\text { 点 } \\
\text { F }\end{array}$ & $\sum_{E-1}^{R}$ & 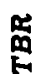 & $\sum_{E=1}^{\infty}$ & 㗂 & $\sum_{i=1}^{R}$ & 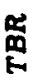 & $\sum_{F}^{\infty}$ & 品 & $\sum_{k}^{R}$ \\
\hline
\end{tabular}

$\begin{array}{lllllllllllllllllllllllllll}\text { Austria } & \ldots & \ldots & \ldots & \ldots & \ldots & \ldots & 1,31 & 1,24 & 1,31 & 1,26 & 1,11 & 1,07 & 0,90 & 0,87 & 0,83 & 0,80 & 0,80 & 0,78 & 0,79 & 0,77 & 0,79 & 0,77 & 0,82 & 0,80 & 0,84 & 0,82\end{array}$ $\begin{array}{lllllllllllllllllllllllllllllll}\text { Bélgica } & \ldots & \ldots & \ldots & \ldots & \ldots & \ldots & 1,24 & 1,19 & 1,27 & 1,22 & 1,09 & 1,06 & 0,84 & 0,82 & 0,84 & 0,81 & 0,83 & 0,80 & 0,82 & 0,80 & - & - & - & - & - & -\end{array}$

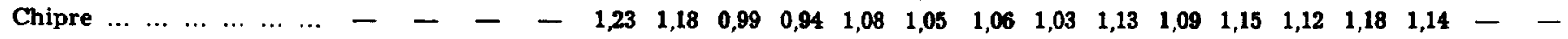
$\begin{array}{llllllllllllllllllllllllll}\text { Dinamarca } & \ldots & \ldots & \ldots & \ldots & \ldots & 1,24 & 1,20 & 1,27 & 1,23 & 0,95 & 0,93 & 0,94 & 0,92 & 0,84 & 0,83 & 0,81 & 0,79 & 0,81 & 0,80 & 0,78 & 0,77 & 0,75 & 0,74 & 0,70 & 0,69\end{array}$ $\begin{array}{lllllllllllllllllllllllllllll}\text { Francia } & \ldots & \ldots & \ldots & \ldots & \ldots & \ldots & 1,33 & 1,29 & 1,39 & 1,34 & 1,21 & 1,17 & 0,94 & 0,92 & 0,89 & 0,87 & 0,91 & 0,89 & 0,89 & 0,87 & 0,91 & 0,89 & 0,96 & 0,94 & 0,96 & 0,94\end{array}$ $\begin{array}{lllllllllllllllllllllll}\text { R. F. de Alemania } & \ldots & \ldots & 1,15 & 1,10 & 1,22 & 1,17 & 0,98 & 0,95 & 0,70 & 0,68 & 0,71 & 0,69 & 0,68 & 0,66 & 0,67 & 0,65 & 0,67 & 0,65 & 0,70 & 0,68 & 0,70 & 0,68\end{array}$

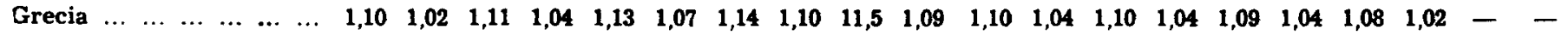
$\begin{array}{llllllllllllllllllllllllllll}\text { Islandia } & \ldots & \ldots & \ldots & \ldots & \ldots & \ldots & 2,02 & 1,95 & 1,78 & 1,72 & 1,36 & 1,32 & 1,29 & 1,26 & 1,21 & 1,19 & 1,13 & 1,11 & 1,15 & 1,13 & 1,22 & 1,19 & 1,21 & 1,19 & - & -\end{array}$ $\begin{array}{llllllllllllllllllllllllll}\text { Irlanda } & \ldots & \ldots & \ldots & \ldots & \ldots & \ldots & 1,86 & 1,80 & 1,97 & 1,85 & 1,88 & 1,81 & 1,65 & 1,60 & 1,61 & 1,56 & 1,58 & 1,53 & 1,59 & 1,54 & - & - & - & - & -\end{array}$ $\begin{array}{lllllllllllllllllllllllllllllllll}\text { Italia } & \ldots & \ldots & \ldots & \ldots & \ldots & \ldots & 1,15 & 1,07 & 1,28 & 1,20 & 1,16 & 1,10 & 1,05 & 1,00 & 0,98 & 0,94 & 0,94 & 0,91 & 0,89 & 0,86 & 0,87 & 0,85 & - & - & - & -\end{array}$

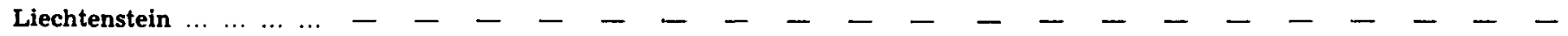

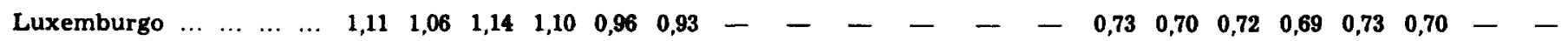

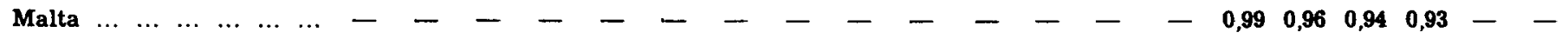
$\begin{array}{llllllllllllllllllllllllllll}\text { Países Bajos } \ldots & \ldots & \ldots & \ldots & \ldots & 1,52 & 1,46 & 1,46 & 1,43 & 1,25 & 1,22 & 0,81 & 0,79 & 0,79 & 0,78 & 0,77 & 0,75 & 0,77 & 0,76 & 0,76 & 0,75 & 0,78 & 0,76 & - & -\end{array}$ $\begin{array}{llllllllllllllllllllllllll}\text { Noruega } & \ldots & \ldots & \ldots & \ldots & \ldots & 1,38 & 1,33 & 1,41 & 1,37 & 1,22 & 1,19 & 0,97 & 0,95 & 0,91 & 0,89 & 0,85 & 0,84 & 0,86 & 0,84 & 0,85 & 0,84 & 0,83 & 0,82 & 0,83 & 0,82\end{array}$ $\begin{array}{ccccccccccccccccccccccccccccc}\text { Portugal } & \ldots & \ldots & \ldots & \ldots & \ldots & 1,50 & 1,31 & 1,50 & 1,36 & 1,34 & 1,23 & 1,26 & 1,19 & 1,26 & 1,19 & 1,21 & 1,14 & 1,11 & 1,05 & 1,06 & 1,00 & - & - & - & -\end{array}$

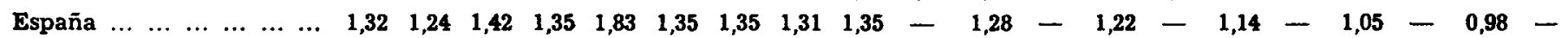
$\begin{array}{lllllllllllllllllllllllllllllll}\text { Suecia } & \ldots & \ldots & \ldots & \ldots & \ldots & \ldots & 1,06 & 1,02 & 1,17 & 1,15 & 0,94 & 0,92 & 0,86 & 0,85 & 0,82 & 0,81 & 0,80 & 0,78 & 0,78 & 0,77 & 0,81 & 0,79 & 0,82 & 0,80 & - & -\end{array}$ $\begin{array}{llllllllllllllllllllllllllll}\text { Suiza } & \ldots & \ldots & \ldots & \ldots & \ldots & \ldots & 1,19 & 1,15 & 1,27 & 1,23 & 1,02 & 1,00 & 0,78 & 0,76 & 0,75 & 0,73 & 0,74 & 0,72 & 0,73 & 0,71 & 0,73 & 0,71 & 0,75 & 0,73 & 0,75 & 0,73\end{array}$

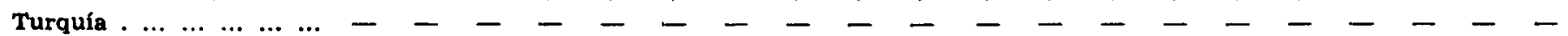

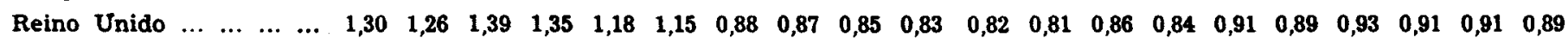


Pero, además, el problema no es sólo que la población europea tenga un peso relativo cada vez menor en el conjunto mundial. Es que su población será cada vez más anciana (mientras que en los países en desarrollo es de acusada juventud). Este hecho tiene también consecuencias respecto a la estructura familiar, puesto que implica que cada vez habrá más adultos viviendo solos y no en familia.

\section{CUADRO 9}

Tasa general de fecundidad (suma de las tasas específicas de fecundidad de mujeres de $15-49$ años). Países del Consejo de Europa, 1960-1981

\begin{tabular}{|c|c|c|c|c|c|c|c|c|c|c|}
\hline & 1960 & 1965 & 1970 & 1975 & 1976 & 1977 & 1978 & 1979 & 1980 & 1981 \\
\hline Austria & 2,69 & 2,68 & 2,30 & 1,84 & 1,70 & 1,65 & 1,63 & 1,62 & 1,68 & 1,71 \\
\hline Bélgica $\ldots \ldots \ldots \ldots$ & 2,52 & 2,59 & 2,24 & 1,74 & 1,73 & 1,70 & 1,70 & - & - & - \\
\hline Chipre $\ldots \ldots \ldots \ldots$ & - & - & 2,54 & 2,01 & 2,25 & 2,23 & 2,29 & 2,39 & 2,47 & - \\
\hline Dinamarca ......... & 2,54 & 2,61 & 1,95 & 1,92 & 1,75 & 1,66 & 1,67 & 1,60 & 1,55 & 1,44 \\
\hline $\begin{array}{ccccc} & \text { Francia } & \ldots & \ldots & \ldots\end{array}$ & 2,73 & 2,84 & 2,47 & 1,32 & 1,83 & 1,87 & 1,83 & 1,87 & 1,96 & 1,97 \\
\hline R. F. de Alemania. & 2,37 & 2,51 & 2,02 & 1,45 & 1,46 & 1,40 & 1,38 & 1,37 & 1,44 & 1,44 \\
\hline Grecia ... ... $\ldots$ & 2,28 & 2,30 & 2,34 & 2,36 & 2,38 & 2,27 & 2,27 & 2,26 & 2,23 & - \\
\hline Islandia $\ldots \ldots \ldots \ldots$ & 4,17 & 3,71 & 2,81 & 2,65 & 2,52 & 2,31 & 2,35 & 2,49 & 2,48 & - \\
\hline $\begin{array}{lllll}\text { Irlanda } & \ldots & \ldots & \ldots & \ldots\end{array}$ & 3,75 & 4,03 & $\mathbf{3 , 8 7}$ & 3,40 & 3,30 & 3,26 & 3,24 & - & - & - \\
\hline $\begin{array}{lllll}\text { Italia } & \ldots & \ldots & \ldots & \ldots\end{array}$ & 2,41 & 2,65 & 2,39 & 2,18 & 2,08 & 1,94 & 1,84 & 1,76 & 1,66 & 1.56 \\
\hline Liechtenstein ... .. & $\therefore$ & - & - & - & - & - & - & - & - & - \\
\hline Luxemburgo $\ldots \ldots$ & 2,28 & 2,34 & 1,97 & - & - & - & 1,50 & 1,48 & 1,51 & - \\
\hline $\begin{array}{lllll}\text { Malta } & \ldots & \ldots & \ldots & \ldots\end{array}$ & - & - & - & - & - & - & - & - & - & - \\
\hline Países Bajos & 3,12 & 3,04 & 2,57 & 1,66 & 1,63 & $1, \mathbf{5 8}$ & 1,58 & 1,56 & 1,60 & 1,57 \\
\hline Noruega . ... & 2,83 & 2,92 & 2,51 & 1,89 & 1,87 & 1,75 & 1,77 & 1,75 & 1,72 & - \\
\hline $\begin{array}{lllll}\text { Portugal } & \ldots & \ldots & \ldots\end{array}$ & 3,07 & 3,07 & 2,75 & 2,58 & 2,58 & 2,48 & 2,28 & 2,17 & - & - \\
\hline $\begin{array}{lllll}\text { España } & \ldots & \ldots & \ldots & \ldots\end{array}$ & 2,78 & 2,90 & 2,83 & 2,80 & 2,79 & 2,66 & 2,52 & 2,31 & 2,16 & 1,99 \\
\hline $\begin{array}{lllll}\text { Suecia } & \ldots & \ldots & \ldots & \ldots\end{array}$ & 2,17 & 2,41 & 1,94 & 1,78 & 1,69 & 1,65 & 1,60 & 1,66 & 1,68 & - \\
\hline Suiza $\ldots \ldots \ldots$ & 2,44 & 2,61 & 2,09 & 1,60 & 1,54 & 1,52 & $1, \mathbf{4 9}$ & 1,50 & 1,53 & 1,53 \\
\hline Turquía $\ldots \ldots \ldots$ & - & - & - & - & - & - & - & - & - & - \\
\hline Reino Unido $\ldots . .$. & 2,69 & 2,86 & 2,44 & 1,82 & 1,75 & 1,70 & 1,77 & 1,88 & 1,92 & 1,87 \\
\hline
\end{tabular}

La falta de capacidad reproductora de las poblaciones europeas se comprueba también mediante la tasa general de fecundidad, cuya interpretación es semejante a la tasa neta de reproducción, pero tomando en cuenta los nacimientos de ambos sexos, varones y mujeres. En todos los países, la tasa correspondiente a 1980 es inferior a la de 1960; y, además, sólo cuatro países tienen una tasa superior a dos (que será el nivel de reemplazo).

\section{Aborto}

Por si todo lo anterior no fuera suficiente, la creciente aceptación del aborto voluntario en la legislación de los países europeo-occidentales, introduce otro elemento a tener en cuenta, aunque de momento su importancia cuantitativa no sea muy grande. 
Los datos del cuadro 10, que contrariamente a los anteriores se ofrecen en cifras absolutas, debido a que son cifras relativamente pequeñas, no dejan lugar a dudas respecto al crecimiento del aborto voluntario. Algunos países, como Suecia - Dinamarca, han multiplicado por 10 el número de abortos entre 1960 y 1980.

\section{CUADRO 10}

Número de abortos legales (en miles).

Países del Consejo de Europa, 1960-1981

\begin{tabular}{|c|c|c|c|c|c|c|c|c|c|c|}
\hline & 1960 & 1965 & 1970 & 1975 & 1976 & 1977 & 1978 & 1979 & 1980 & 1981 \\
\hline $\begin{array}{lllll}\text { Austria } & \ldots & \ldots & \ldots & \ldots\end{array}$ & 18,9 & 18,7 & 15,6 & 26,4 & 25,4 & 23,4 & 23,6 & 23,0 & 23,4 & - \\
\hline $\begin{array}{lllll} & & & \ldots & \ldots \\
\end{array}$ & - & - & - & - & - & - & - & - & - & - \\
\hline Chipre $\ldots \ldots \ldots$ & - & - & - & - & - & - & - & - & - & - \\
\hline Dinamarca $\ldots \ldots \ldots$ & 3,9 & 5,2 & 9,1 & 27,9 & 26,8 & 25,7 & 23,7 & 23,2 & 23,3 & 23,0 \\
\hline 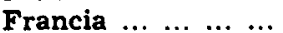 & - & - & - & 33,4 & 134,2 & 150,9 & 150,4 & 156,8 & 171,3 & - \\
\hline R. F de Alemania. & 一 & - & 一 & - & - & 54,3 & 73,5 & 82,8 & 87,7 & 87,5 \\
\hline $\begin{array}{ccccc}\text { Grecia } & \ldots & \ldots & \ldots & \ldots\end{array}$ & - & - & - & - & - & - & - & - & - & - \\
\hline Islandia $\ldots \ldots \ldots$ & 0,1 & 0,1 & 0,1 & 0,3 & 0,4 & 0,4 & 0,5 & 0,5 & 0,5 & 0,5 \\
\hline $\begin{array}{lllll} & & \ldots & \ldots & \ldots\end{array}$ & - & - & - & - & - & - & - & - & - & - \\
\hline 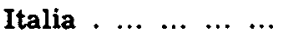 & - & 一 & 一 & 一 & 一 & 一 & - & 187,8 & 220,3 & - \\
\hline Liechtenstein $\ldots \ldots$ & - & - & - & - & - & - & - & - & - & - \\
\hline $\begin{array}{ccc}\text { Luxemburgo } & \ldots & \ldots\end{array}$ & - & - & - & - & - & - & - & - & - & - \\
\hline $\begin{array}{lllll}\text { Malta } & \ldots & \ldots & \ldots & \ldots\end{array}$ & - & - & - & - & - & - & - & - & - & - \\
\hline Países Bajos ... ... & - & - & - & 15,0 & 14,8 & 16,1 & 15,3 & 16,6 & 19,7 & 19,5 \\
\hline Noruega . ......... & - & 3,5 & 7,9 & 15,1 & 14,8 & 15,5 & 14,8 & 14,5 & 13,5 & 13,8 \\
\hline Portugal . ... ... ... & - & - & - & - & - & - & - & - & - & 一 \\
\hline $\begin{array}{lllll}\text { España } & \ldots & \ldots & \ldots & \ldots\end{array}$ & - & - & - & - & - & - & - & - & - & - \\
\hline $\begin{array}{lllll}\text { Suecia } & \ldots & \ldots & \ldots & \ldots\end{array}$ & 2,8 & 6,2 & 16,1 & 32,5 & 32,4 & 31,5 & 31,9 & 34,7 & 34,9 & 33,0 \\
\hline $\begin{array}{lllll}\text { Suiza } & \ldots & \ldots & \ldots & \ldots\end{array}$ & - & - & - & - & - & - & - & - & - & - \\
\hline Turquia . ... ... ... & . & - & - & - & - & - & - & - & - & - \\
\hline Reino Unido ... ... & - & - & 81,2 & 113,5 & 109,1 & 110,0 & 119,3 & 128,4 & 136,8 & - \\
\hline
\end{tabular}

Los datos de este cuadro pueden ser útiles también para demostrar la poca fiabilidad de la cifra que se suele manejar para España.

En efecto, es corriente manejar la cifra de 300.000 abortos voluntarios anuales en España (o de españolas fuera de España). Lo exagerado de esta cifra se pone fácilmente de manifiesto cuando se toma en cuenta que:

a) El total de nacimientos anualmente en España se encuentra próximo a 600.000 .

b) Francia, con una población mayor que la de España, y con el aborto legalizado hace bastantes años, sólo tuvo 171.300 abortos en 1980 . Incluso Italia, con población superior a la de España y aborto legalizado muy recientemente, sólo llega a los 220.300 anuales.

c) Por consiguiente, la cifra de abortos en España (o por españolas en el extranjero) no parece que pueda sobrepasar actualmente la cifra de 100.000 anuales. 
CONSIDERACIONES FINALES SOBRE LA FAMILIA EN EUROPA OCCIDENTAL

Llegados a este punto parecen quedar ampliamente demostrados los cambios importantes que se están produciendo en las estructuras familiares europeas, y que podrían resumirse, como tendencias, de la siguiente manera:

1. Disminución del número de matrimonios.

2. Aumento de las relaciones prematrimoniales y de la cohabitación.

3. Retraso en la edad al casarse.

4. Reducción de la ruptura de hogares a causa de la muerte de uno de los cónyuges, $y$, en todo caso, retraso en la ruptura de hogares por esta causa (debido a la disminución de la mortalidad).

5. Aumento de la ruptura de hogares a causa del divorcio (y de las separaciones $\mathrm{y}$ anulaciones matrimoniales).

6. Incremento de hogares de una sola persona (por aumento de los solteros emancipados, por rupturas de hogares a causa del divorcio o similar y por ruptura de hogares a causa de la muerte de uno de los cónyuges, dada la creciente diferencia de esperanza de vida de las mujeres respecto a los varones, y la menor costumbre social de que los ancianos vivan con alguno de sus hijos).

7. Incremento de hogares con un solo progenitor (padre o madre) por incremento de las rupturas por divorcio o similar.

8. Incremento, por consiguiente, del número de niños educados por un solo progenitor o por un padrastro o madrastra.

9. Aumento de la natalidad ilegítima (es decir, fuera de matrimonios legalmente constituidos).

10. Disminución de la natalidad global de cada país.

11. Reducción del número de hijos.

12. Retraso en la edad al tener los hijos, pero al mismo tiempo, reducción del período de tiempo en que se tienen.

13. Reducción de la capacidad reproductora de la población por debajo del nivel de reemplazamiento.

14. Incremento del número de abortos voluntarios que en algunos países representan un tercio del número de nacidos vivos.

Es evidente que estos hechos, que tienen suficiente respaldo en los datos, están provocando cambios muy fundamentales en la estructura y funciones de la familia europea occidental que aquí no han sido ni siquiera examinados (relaciones entre los cónyuges, relaciones padres-hijos, relaciones con otras familias, etc.).

Roussel y Festy, en el trabajo citado, proponen una tipología de las sociedades europeas de acuerdo con los cambios ya producidos en las dimensiones de la familia cuyos datos se han examinado aquí. Concretamente distinguen cuatro tipos que se resumen a continuación:

I. Las relaciones sexuales comienzan básicamente en el matrimonio. Las prácticas anticonceptivas son fundamentalmente naturales. El aborto es ilegal o muy condicionado y limitado. La edad al casarse probablemente se está adelantando. 
II. Aumentan las relaciones prematrimoniales, pero con intención de formalizarse en matrimonio. Se extiende el uso de anticonceptivos entre los jóvenes solteros. A pesar de ello aumenta el número de embarazos prematrimoniales, y el aborto comienza a ser una alternativa al matrimonio «forzoso». Incremento en el número de separaciones y divorcios.

III. La cohabitación comienza a ser una alternativa al matrimonio, pero la natalidad sigue fundamentalmente ligada al matrimonio. Utilización de métodos anticonceptivos cada vez más eficaces, y en caso de fallo, recurso cada vez más frecuente al aborto voluntario. Legalización de métodos anticonceptivos y aborto. La procreación, de ser sólo consecuencia de la nupcialidad, comienza a convertirse en causa de la nupcialidad. Retraso en la edad al casarse.

IV. Generalización de la cohabitación prematrimonial durante varios años. La natalidad ya no está necesariamente ligada al matrimonio, y, por tanto, incremento de la natalidad extramatrimonial (que ya no recibe la denominación de ilegítima). Aumento continuado de la divorcividad. Extensión de la esterilización voluntaria. Indiferencia social hacia el estado civil de las parejas.

No sólo cada sociedad europea occidental se encuentra más próxima a alguno de estos tipos, sino que los diferentes grupos dentro de cada sociedad pueden estar próximos a diferentes tipos también.

Si tenemos en cuenta los datos relativos a España, parece que puede concluirse que, a nivel global, estaría pasando de la II a la III etapa, aunque, por supuesto, existan grupos sociales con pautas de comportamiento típicas de cada una de las cuatro etapas.

Y para terminar, puede ser ilustrativo volver a citar a los autores de este singular informe, que resumen así la situación:

«Lo cierto es que la mayor parte de los estados miembros (del Consejo de Europa) han entrado en una fase de actitudes y comportamientos cambiantes en cuestiones de matrimonio. Estamos asistiendo a la desaparición de ideas y normas que fueron corrientes hace diez años. El sistema con el que estábamos familiarizados se está desintegrando paulatinamente, y todavía no ha aparecido el esquema de una nueva pauta consistente. No estamos suficientemente alejados de estos cambios como para poder decidir con rigor científico si el incuestionable cambio que se ha producido es simplemente un cambio coyuntural o fundamental. Sería poco inteligente, sin embargo, aceptar sin reservas la teoría de que estamos asistiendo a una moda pasajera y esperar simplemente a que todo vuelva a su sitio. Hay suficiente evidencia de que lo que está sucediendo no es una pequeña reordenación de las pautas familiares, sino un cambio profundo en una dirección todavía difícil de determinar, y cuyas consecuencias son difíciles de prever.» 


\section{BIBLIOGRAFIA}

Bourgzors-Pichut, J.: "The demographic transition in Europe", European Population Conference 1982, EPC (82) 8-E, Council of Europe, Strasbourg, 1982 (mimeografiado).

Van den BrzkrI, J. C.: "La politique démographiques dans la région du Conseil de l'Europe: Quelles politiques adopter devant la faiblesse de la fecondité?", European Population Conference 1982, EPC (82) 15-F, Council of Europe, Strasbourg, 1981 (mimeografiado).

Van den BREkel, J. C.: "Population policies in the Member States of the Council of Europe, specially policies relating to fertility trends", CDDE (81) 6 revised, Council of Europe, Strasbourg, 1981 (mimeografiado).

COOPER, D.: The death of the family, Penguin books, Middlesex, 1973.

Cressars, J. C.: "Fertility and the State", European Population Conference 1982, EPC (82) 16-E, Council of Europe, Strasbourg, 1982 (mimeografiado).

DiEz NicolAs, J.: "Survey of the country reports", European Population Conference 1982, EPC (82) 16-E, Council of Europe, Strasbourg, 1982 (mimeografiado).

Frsty, P.: "La Fecondité en Europe Meridionale et en Irlande: Analyse et Perspectives", ED-FE 6 (80) revised, Council of Europe, Strasbourg, 1981 (mimeografiado).

Goope, W J.: World Revolution and family patterns, the Free Press, New York, 1970.

GORDON, M.: The nuclear family in crisis: the search for an alternative, Harper and Row, New York, 1972.

Horrmank-Nowotny, M. J.: "Structural and Cultural Consequences of future european demographic development", European Population Conference 1982, EPC (82) 13-E, Council of Europe, Strasbourg, 1982 (mimeografiado).

KIRK, M.: Demographic and Social Change in Europe, 1975-2000, Liverpool University Press, Liverpool, 1981.

KIRK, M.: "La situation et les perspectives démographiques dans les Etats Membres du Conseil de l'Europe", CAHED 30 (78) définitif, Conseil de l'Europe, Strasbourg, 1978 (mimeografiado).

KIRK, M.: "Perspectives of demographic change in Europe", European Population Conference 1982, EPC (82) 9-E, Council of Europe, Strasbourg, 1982 (mimeografiado).

Kooy, G. A.: "Evolution démographique et autres phénomènes sociaux en Europe", European Population Conference 1982, BPC (82) 12-F, Council of Europe, Strasbourg, 1982 (mimeografiado).

MORSA, J.: "Constitution et dissolution des familles: structures familiales", European Population Conference 1982, EPC (82) 2-F, Council of Europe, Strasbourg, 1982 (mimeografiado).

Rousser, L., y P. Festy: "Recent trends in attitudes and behaviour affecting the family in Council of Europe Member States", Population Studies No. 4, Council of Europe, Strasbourg, 1978.

SrmoNs, J.: "Fertility control in Europe", European Population Conference 1982, EPC (82) 3-E, Council of Europe, Strasbourg, 1982 (mimeografiado).

Strering Committee on Population: "Exchange of views on marriage, divorce and remarriage", CDDE (82) 14 revised, Council of Europe, Strasbourg, 1982 (mimeografiado).

Streninc Committex on Population: "Recent demographic developments in the Member States of the Council of Europe", Strasbourg, 1982 (mimeografiado).

Watrelar, Ch.: "General Review of the demographic situation and trends in Europe", European Population Conference 1982, EPC (82) 2-F, Council of Europe, Strasbourg. 1982 (mimeografiado). 